\title{
Combined jugular and femoral approach for treating severe tricuspid valve regurgitation
}

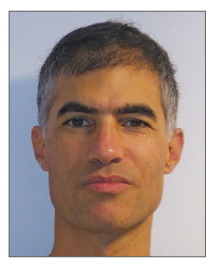

Amnon Eitan, MD; Claudia Tiburtius, MD; Julian Witt, MD; Joachim Schofer*, MD, PhD Albertinen Heart Center, Hamburg, Germany

This paper also includes supplementary data published online at: http://www.pcronline.com/eurointervention/128th_issue/248
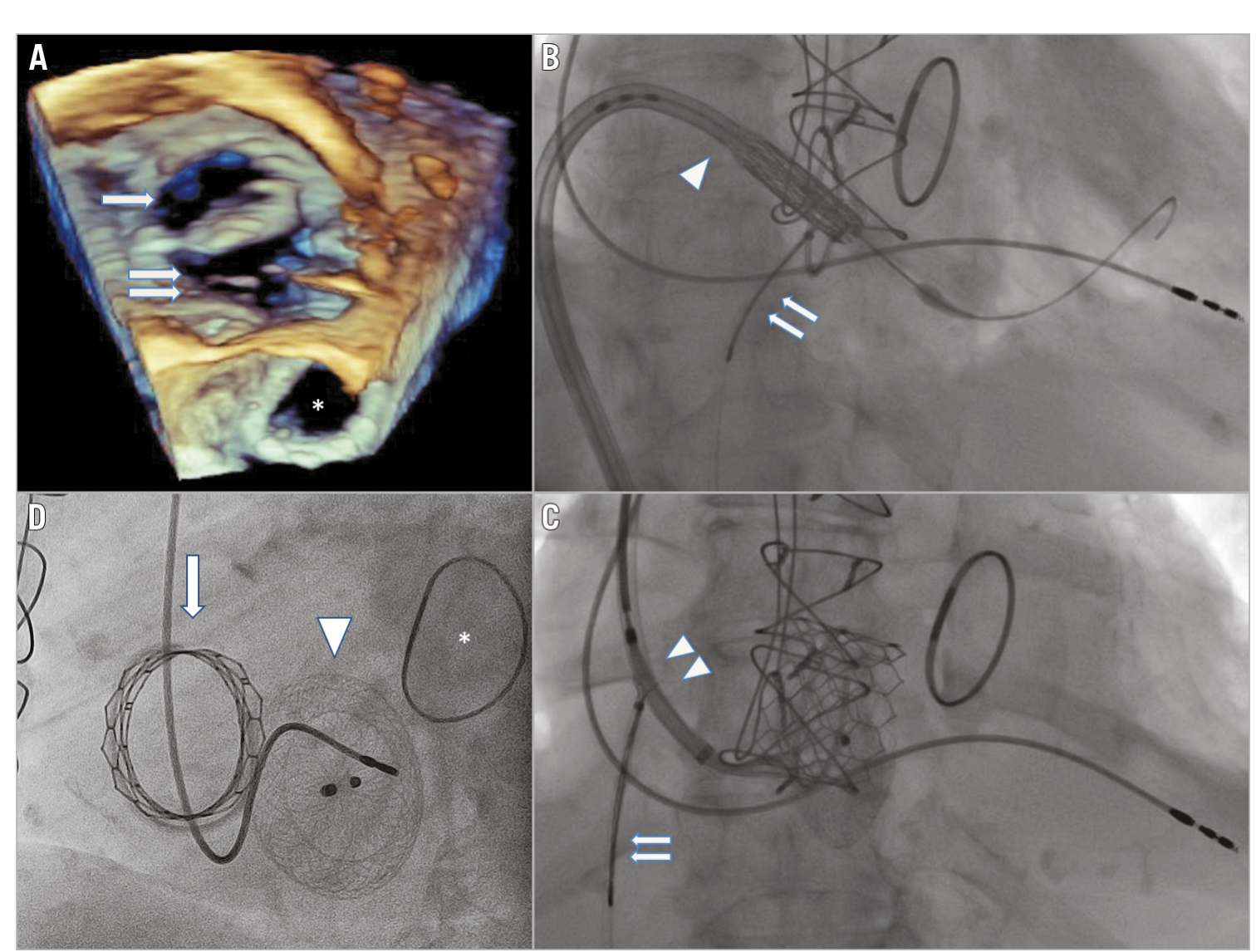

*Corresponding author: Albertinen Heart Center, Wördemannsweg 25-27, 22527 Hamburg, Germany. 
In 2013, a 78-year-old lady underwent surgery for reconstruction of her mitral valve with a $30 \mathrm{~mm}$ Carpentier-Edwards Physio annuloplasty ring (Edwards Lifesciences, Irvine, CA, USA) and reconstruction of her tricuspid valve with a $32 \mathrm{~mm}$ Carpentier-Edwards Physio tricuspid annuloplasty ring (Edwards Lifesciences). Gradually, a severe tricuspid regurgitation developed with heart failure of NYHA Class III.

Current echocardiography demonstrated high-grade tricuspid regurgitation with both a valvular and a large paravalvular (PV) regurgitation (Panel A: arrow - tricuspid ring; double arrow giant PV space sized $34 \times 36 \mathrm{~mm}$; * mitral ring). Considering the patient's high risk, the Heart Team decided to attempt a percutaneous intervention.

Through a right femoral vein approach, a $29 \mathrm{~mm}$ Edwards SAPIEN 3 valve (Edwards Lifesciences) was introduced and positioned in the tricuspid valve ring. The help of a snare introduced through the contralateral femoral vein was required due to the difficult angle passing from the inferior vena cava (IVC) into the right ventricle (Panel B: arrowhead - SAPIEN 3; double arrow - snare).

For the next stage, we used a $28 \mathrm{~mm}$ AMPLATZER ${ }^{\circledR}$ Septal Occluder (St. Jude Medical, St. Paul, MN, USA) for sealing the paravalvular leak. Attempts to position the device through a right femoral vein approach failed; therefore, we switched to a right jugular vein approach to achieve a better angle. With the help of a snare introduced through the femoral vein (Panel C: double arrowhead - Occluder guide; double arrow - snare) (Moving image 1), the Occluder was placed and released in the correct position in the paravalvular space. Follow-up fluoroscopy showed the devices to be well positioned (Panel D: arrow - SAPIEN 3; arrowhead-Occluder; * mitral ring).

Percutaneous procedures of the tricuspid valve are difficult, mainly because of the angle of approach. The use of both the jugular and the femoral approach and the help of a snare may facilitate this procedure.

\section{Conflict of interest statement}

The authors have no conflicts of interest to declare.

\section{Supplementary data}

Moving image 1. Manipulation of the AMPLATZER Occluder delivery sheath introduced from the jugular approach with the help of a snare introduced from the femoral approach.

The supplementary data are published online at:

http://www.pcronline.com/

eurointervention/128th_issue/248 